\title{
FERNANDO CARDIM DE CARVALHO, SISTEMAS FINANCEIROS E O FINANCIAMENTO DA ACUMULAÇÃO
}

\author{
Rogério Studart ${ }^{a}$ \\ Antonio José Alves Jr. ${ }^{b}$ \\ ${ }^{a}$ Colaborador Sênior no World Resources Institute. Washington DC, EUA. ORCID: https://orcid. \\ org/0000-0002-2394-4237.

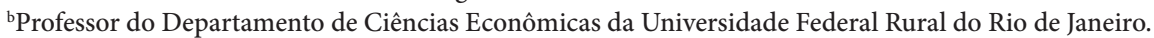 \\ Seropédica, RJ, Brasil. ORCID: https://orcid.org/0000-0002-4298-7590.
}

Recebido em 31 dezembro 2018

Aceito em 31 outubro de 2019

RESUMO: Este artigo revisita as contribuições do professor Fernando Cardim de Carvalho sobre o tema do financiamento da acumulação de capital nas economias monetárias. Destaca duas funções que, idealmente, devem ser cumpridas pelo setor financeiro para permitir que as economias de mercado sustentem o crescimento e evitem instabilidade financeira. A primeira diz respeito à garantia da oferta adicional de liquidez criada por aumentos na produção e investimento (motiva finanças). A segunda refere-se à provisão de mecanismos para financiar empreendimentos de longo prazo, amenizando, portanto, a tendência à fragilidade financeira (financiamento) ao longo deste processo. $\mathrm{O}$ artigo baseia-se nos fundamentos apresentados por Cardim para sugerir que as instituições financeiras privadas muitas vezes não conseguem cumprir essas funções devido a problemas informativos e incertezas, especialmente na fase de transformação estrutural. Conclui defendendo a necessidade de políticas públicas para desenvolver mercados financeiros e instrumentos adequados para apoiar o desenvolvimento econômico, que envolve investimentos transformacionais.

PALAVRAS-CHAVE: sistema financeiro; financiamento da acumulação de capital; preferência pela liquidez; política de desenvolvimento financeiro

\section{CLASSIFICAÇÃO JEL: E12; E44.}




\title{
FERNANDO CARDIM DE CARVALHO, FINANCIAL SYSTEMS, AND THE FINANCING OF CAPITAL ACCUMULATION
}

\begin{abstract}
This paper revisits the contributions of Professor Fernando Cardim de Carvalho on the theme of the financing of capital accumulation in monetary economies. It highlights two functions that ideally should be fulfilled by the financial sector to allow market economies to sustain growth and avoid financial instability. The first one relates to ensuring the additional supply of liquidity created by hikes in production and investment (finance motive). The second refers to the provision of mechanisms to fund long-term undertakings, therefore softening the tendency to financial fragility (funding) along the process. The article builds on the foundations put forth by Cardim to suggest that private financial institutions often fail to fulfill these functions due to informational problems and uncertainty, especially in the phase of structural transformation. It concludes by advocating the need for public policies to develop financial markets and instruments that are appropriate to support economic development, which involves transformational investments.
\end{abstract}

KEYWORDS: financial system; financing of capital accumulation; liquidity preference; financial development policy. 


\section{INTRODUÇÃO}

Fenômenos monetários e financeiros afetam decisões cruciais de agentes na determinação da dinâmica, do produto, do emprego e da trajetória de longo prazo das economias de mercado. Em torno dessa conclusão, extraída dos escritos de John Maynard Keynes, o professor Cardim de Carvalho, um dos expoentes da escola pós-Keynesiana, organizou parte significativa de suas investigações. Seus escritos, em geral, se voltam para discussões teóricas em torno desses temas, mas são inegáveis as implicações profundas para o debate e a formulação de políticas econômicas.

Um dos pontos de partida para entender a visão de Cardim ${ }^{1}$ sobre fenômenos monetários e financeiros é, evidentemente, o princípio da demanda efetiva (PDE) apresentado por Keynes, na sua Teoria Geral (TG), publicada em 1936. O PDE implica que as forças de mercado, quando atuando livremente, quase nunca levam ao pleno emprego e à eficiente utilização dos recursos, contrariando não apenas a visão prevalecente à época do lançamento da Teoria Geral, como também aquela predominante nos cursos de macroeconomia contemporâneos.

Não é por outro motivo que soa estranha para muitos, até hoje, a conclusão de que, mesmo em condições de concorrência perfeita, o equilíbrio macroeconômico de pleno emprego é uma exceção, e a regra são resultados subótimos de bem-estar coletivo. Isso não significa que a organização dos mercados não importa. Significa apenas que, como Cardim insistiu com frequência, as relações macroeconômicas têm autonomia frente à microeconomia. É esse ponto de partida que permitiu a Keynes postular que políticas econômicas poderiam - e deveriam- corrigir uma das grandes falhas das economias monetárias.

Um segundo corolário do PDE, implícito na discussão do papel do investimento (ou da acumulação de capital) na dinâmica macroeconômica, se relaciona à visão convencional de que o sistema financeiro pode ser entendido como um simples intermediário de poupanças individuais - e de que um mercado competitivo geraria por si só as condições necessárias para o financiamento do investimento com plena e eficiente utilização de recursos. Esse é um tema explorado exaustivamente, e sob diversos ângulos, por Cardim de Carvalho (por exemplo, em CARVALHO, 1992 e 1996) - especialmente nas suas análises sobre dois aspectos do sistema financeiro na dinâmica das economias monetárias modernas: a provisão de liquidez para a aquisição de bens de capital e a mitigação da

\footnotetext{
Para manter o rigor das referências bibliográficas, utilizamos o último sobrenome daquele autor (e.g. CARVALHO, 1992). Nas demais passagens, nos referimos a ele pelo nome cuja grande maioria dos seus alunos e discípulos o chamava: Cardim.
} 
exposição ao descasamento de prazos inerentes ao financiamento do processo de acumulação. No arcabouço teórico pós-Keynesiano, trata-se, respectivamente, dos conhecidos problemas de finance e funding da acumulação de capital.

Este artigo revisita, sem qualquer pretensão de esgotá-la, a contribuição do professor e do mestre Cardim sobre o tema do financiamento da acumulação de capital em economias de mercado. Na próxima seção, discutimos como Cardim aborda, teoricamente, o "circuito finance-funding". Na terceira seção, ampliamos um pouco mais a discussão do tema do papel da incerteza (em contraposição ao conceito de risco) na alocação de estoques de riqueza financeira e no funding da acumulação. Na quarta seção, abrimos as portas para as implicações do desenvolvimento institucional financeiro na delimitação das condições de financiamento. A última seção resume nossa análise e apresenta nossas conclusões.

\section{FINANCIAMENTO, INVESTIMENTO E POUPANÇA}

No livro Mr. Keynes and the Post-Keynesians, Cardim (CARVALHO, 1992) delineia sua interpretação dos fundamentos da Teoria Geral de Keynes, calcada no princípio da demanda efetiva (PDE). Este último, como já mencionado, demonstra que, mesmo em situação de perfeita competição - com perfeita distribuição de informações e preços flexíveis de fatores e bens -, o equilíbrio macroeconômico raramente ocorre no pleno emprego, como suposto pela teoria econômica clássica. Dadas as condições técnicas, que definem a capacidade produtiva, e a propensão marginal a consumir, o equilíbrio macroeconômico dependeria essencialmente do nível agregado do investimento - e, portanto, das expectativas de longo prazo dos empresários e das condições de financiamento da acumulação.

Um dos corolários da PDE é o de que seria falaciosa a visão prevalecente no pensamento ortodoxo vigente, não só no tempo da publicação da TG, mas também hoje, de que uma redução dos salários reais seria o caminho natural para a redução do desemprego e a reversão das crises de produção. Ao contrário, Keynes (1936) afirma que a adoção de tal receita de política econômica poderia agravar a situação de desemprego em uma economia competitiva, na medida em que deprimiria a demanda agregada e reduziria o incentivo a investir. Para o Keynes (1936) e os pós-Keynesianos, a receita correta para combater o desemprego involuntário deveria considerar os dois principais determinantes da dinâmica macroeconômica, a saber, as expectativas de longo prazo e as condições de financiamento da acumulação.

Para Cardim de Carvalho, a TG seria somente o ponto de partida para a discussão de temas de financiamento da acumulação. Apenas em artigos posteriores à TG, Keynes 
aprofundaria sua visão sobre os determinantes das condições de financiamento do investimento, isto é, custos e volumes ofertados, à luz do princípio da demanda efetiva. ${ }^{2} \mathrm{O}$ tema central desses artigos envolve pelo menos um resultado lógico do princípio da demanda efetiva: a reversão da causalidade entre investimento e poupança. ${ }^{3}$ Com essa reversão, Keynes abre um debate importante para a maioria dos seus interlocutores, críticos ou não, em torno de duas questões: o que determinaria as "condições de financiamento" na TG? Qual o papel desempenhado pelos sistemas financeiros nas economias de mercado para além da intermediação de poupança?

Como demonstra Cardim (CARVALHO, 1996, 1997 e 2012), o tema é resolvido de forma muito preliminar na TG: a taxa de juros - que é somente uma parte do custo de capital - é determinada pela oferta e demanda por liquidez. Keynes teria assim deixado um flanco aberto aos críticos que procurariam demonstrar que a teoria da preferência pela liquidez nada mais seria do que uma visão disfarçada da teoria dos fundos emprestáveis (TFE). Esta última, como se sabe, estabelece que a poupança agregada, calcada em decisões de maximização intertemporal, é, em última instância, seria o determinante do volume e das condições de financiamento - algo que Keynes rejeitará de forma veemente.

De fato, em verdadeiros "ensaios de persuasão", Keynes, em artigos posteriores à Teoria Geral, procura explicitar como suas ideias diferem da TFE ao rediscutir a sua teoria da preferência pela liquidez para a determinação das taxas de juros. Adicionalmente, e para tornar ainda mais explícita sua visão especial sobre o financiamento da acumulação em economias de mercado, Keynes detalha os papeis das instituições (bancárias e não-bancárias) e dos mercados financeiros na determinação das condições de financiamento. É a partir dessa discussão, do que se convencionou a chamar do circuito finance-funding. E a partir desses artigos que o professor Cardim, em diversos artigos (CARVALHO, 1996, 1997, 2009a, 2012, 2015, 2016) pode construir sua visão sobre o papel dos fenômenos e dos sistemas financeiros na determinação das economias de mercado.

2 Para uma análise dos fundamentos da teoria de Keynes em uma interpretação pós-Keynesiana, ver Carvalho (1992, parte I).

3 Pelo princípio da demanda efetiva, o investimento é o determinante último (causa causans) do nível de produto e da renda agregada. Logo o investimento precede logicamente a poupança agregada. Por conseguinte, a taxa de juros não poder ser a variável que equilibra poupança e investimento agregado como determinada a TFE. 


\subsection{FINANCE E PROVISÃO DE LIQUIDEZ}

Uma das primeiras incursões de Cardim sobre o tema do financiamento do investimento se associa ao motivo finanças (CARVALHO, 1992, 1996). Sua interpretação pode ser resumida da seguinte forma: para Keynes, bancos comerciais podem prover liquidez necessária ao ato de investir, na medida em que criam dinheiro ex-nihilo - já que depósitos à vista, que são aceitos como meios de pagamento, são comumente criados como uma operação contábil por bancos comerciais.

Porém, o fato de poderem criar ex-nihilo meios de pagamento não dá aos bancos comerciais poderes ilimitados - afinal, eles têm a obrigação de converter, ao par e imediatamente, seus depósitos à vista em moeda governamental, sempre que demandados. Por essa característica de sua estrutura de balanço, os bancos comerciais ofertam crédito com prazos curtos, administrando suas reservas de acordo com os fluxos esperados de saque em espécie. Aqui começa o que Cardim intitula "dilema da liquidez":

the liquidity dilemma is intrinsic to the dynamics of a monetary economy. The same financial structures that allow productive investment and capital accumulation, and economic growth, to reach the levels characteristic of modern capitalist economies are also those where fragilities are accumulated that ultimately cause deep crises, such as the one that began in the U.S. economy in 2007 and has since spread throughout most of the world. (CARVALHO, 2016, p. 306)

O dilema pode ser colocado ainda de outra forma. Suponha que uma empresária financie a construção de uma fábrica, com início de produção em um par de anos, com crédito bancário de curto prazo. Nesse caso, ela estaria se submetendo a rolagens contínuas de seus financiamentos de curto prazo, estando, portanto, vulnerável a mudanças de taxas de juros e/ou flutuações de liquidez. ${ }^{4}$ Essa situação de vulnerabilidade não é ideal nem para o banco, nem para o tomador - já que ambos se submetem a riscos e custos de inadimplência. Caso o banco comercial aceite financiá-la com crédito de longo prazo, será o banqueiro que assumirá os riscos de descasamento no seu balanço.

4 Nesse sentido, o prazo do crédito - ou a preferência pela liquidez dos bancos - será influenciada pelos arranjos institucionais que dão aos bancos maior ou menor segurança em assumir tais descasamentos. Logo, quanto mais organizado o mercado interbancário ou de títulos diversos, maior o volume de ativos bancários que pode ser convertido em moeda instantaneamente, diminuindo a importância da janela de redesconto. Alternativamente, se forem pouco organizados, confere-se papel especial à operação das janelas de redescontos do Banco Central para prover moeda para os bancos. Em ambos os casos, quanto mais punitivo o uso das janelas de redesconto, menos os bancos estarão dispostos a ampliar sua exposição ou o montante de seus empréstimos para dado nível de reservas. 
Como denota Cardim (CARVALHO, 1996, 2016; CARVALHO et al., 2019), a existência ou não de mecanismos de financiamento de longo prazo influenciará, decisivamente, a forma pela qual serão estruturadas as posturas financeiras dos agentes. Portanto, a institucionalidade do setor financeiro passa a ter relevância para se entender o papel dos atores e mercados financeiros na dinâmica das economias monetárias. E, tal como apontam Schumpeter (1939), Zysman (1983), entre outros autores, o surgimento do sistema de moeda fracionaria, e de bancos comerciais capazes de criar moeda utilizando de simples expansão de seus balanços, seria, para Keynes, um divisor d'aguas na capacidade das economias de mercado de ampliar seus investimentos - muita além do que Marx denominou de acumulação primitiva de riqueza e de reservas de poder de compra - e.g. metais preciosos. ${ }^{5}$

De fato, a partir da existência de bancos comerciais, um aumento da demanda de financiamento do investimento pode ser atendido por simples expansão de crédito, ou pelo apetite dos bancos em saciar essa demanda. Ou seja, o limite ao financiamento da acumulação não seria a decisão do "poupador", mas a preferência pela liquidez dos banqueiros. Este é um tema que o próprio Cardim (cf. CARVALHO 1997, 2009b) revisita com frequência e no qual parcialmente se ancora a teoria de fragilidade financeira (TFF) de Hyman Minsky (1982): os ciclos de crescimento em economias de mercado ocorrem comumente quando se alinham ao entusiasmo dos investidores e dos agentes provedores de crédito.

Dialogando com a TFF, Cardim sempre insistiu em que são nestes momentos que também florescem as inovações que economizam reservas (CARVALHO, 2009), ampliando a capacidade do sistema financeiro de expandir a oferta de moeda. Alternativamente, as autoridades monetárias, premidas pelo crescimento dos negócios e pela necessidade dos bancos, podem se ver, ao menos inicialmente, obrigadas a acomodar as necessidades de reservas de todo o sistema, ${ }^{6}$ sancionando as demandas dos bancos decorrentes do aumento dos financiamentos requeridos pela elevação do nível de investimentos. Como se sabe, para Minsky, essa era a origem dos booms de crédito, momento em que se eleva o volume de financiamento do investimento, mas em que se

5 Como Chick $(1986,1993)$ chama a atenção, a teoria monetária e financeira de Keynes, juntamente, portanto, com todo o chamado circuito finance-funding do financiamento da acumulação, seria calcado em uma inovação financeira relacionada aos estágios de desenvolvimento do banco comercial moderno.

6 As inovações financeiras como método de economia de reservas e criação de crédito são objeto de estudo de diversos autores, como, por exemplo, os trabalhos seminais de Gurley e Shaw (1955) e Minsky (1982), enquanto a acomodação compulsória da demanda de reservas por parte da autoridade monetária é privilegiada por Moore (1988). 
amplia a fragilidade financeira, cuja evolução pode provocar uma crise e a interrupção de uma fase de crescimento. ${ }^{7}$

Antes de discutir com maior detalhes como Cardim vê o tema da fragilidade e o papel das inovações financeiras, parece fundamental falar de outra parte fundamental na abordagem: a discussão do tema do funding na teoria pós-Keynesiana.

\subsection{FUNDING, DESCASAMENTOS E ESTRUTURAS FINANCEIRAS}

$\mathrm{Na}$ discussão do motivo finanças, Cardim revela dois aspectos inerentes aos setores financeiros modernos em economias de mercado. Por um lado, como já vimos, a existência de bancos comerciais cria uma enorme capacidade de alavancar o financiamento da acumulação. Por outro, progressivamente expõe a economia a choques, na medida em que estimula defasagens entre posições ativas e passivas de dois dos principais atores no processo: bancos e investidores produtivos. Esse é, como vimos, o dilema da liquidez tão ressaltado por Cardim, mas é, também, a ponte para a discussão do papel de mercados de títulos financeiros no financiamento da acumulação - e do chamado funding.

Mais uma vez, o estágio de evolução dos sistemas financeiros importa para equacionar esse dilema. Por exemplo, na maioria das economias industriais, tantos as instituições financeiras quanto os investidores produtivos podem definir uma estratégia de financiamento ao longo do ciclo do investimento realizado. $\mathrm{Na}$ realidade, quanto maior for a flexibilidade do setor financeiro para oferecer instrumentos com distintos prazos, características de risco e custo, maior será sua influência sobre a dinâmica macroeconômica.

A institucionalidade importa, mas são múltiplas as institucionalidades possíveis para que o setor financeiro cumpra os papeis necessários - especialmente na sua função de funding. Um exemplo de institucionalidade sobressai do circuito finance-funding, citado por Keynes (1937): os investidores de longo prazo adquirem um "empréstimo-ponte" para executarem seus projetos de investimento, para, posteriormente, emitirem títulos de dívidas de longo prazo ou ações. A venda inicial desses títulos de

\footnotetext{
7 Mesmo em períodos de relativa estabilidade financeira, outras "disfuncionalidades" podem surgir do fato de bancos terem um papel tão crucial no financiamento. Por exemplo, em momentos de expansão, a demanda de crédito pode entrar em descompasso com a preferência pela liquidez dos bancos, que transparece na forma de racionamento de crédito, i.e., na maior seletividade, na exigência de mais garantias e na elevação dos spreads bancários para cliente "não preferenciais" - como por exemplo, pequenas e médias empresas ou startups. Por outro lado, evita-se o aumento na participação em operações vinculadas a projetos de maior "risco percebido", como os de infraestrutura e atividades inovadoras.
} 
longo prazo é realizada nos mercados primários, que são, portanto, fundamentais para o esquema.

Como Keynes (1937) ressalta, com os gastos de investimento, surge, imediatamente, um volume adicional de poupança exatamente igual aos investimentos. O problema relevante não é a falta de poupança, inicialmente mantida nos portfólios como meios de pagamento. $\mathrm{O}$ problema é a forma pela qual os poupadores decidirão alocar os meios de pagamento poupados em ativos financeiros, diante do dilema liquidez-retorno. É desse dilema que emerge a importância capital dos mercados secundários no funding da acumulação de capital.

A intensidade, ou volume diário de transações de compra e venda de títulos existentes, nos mercados secundários, dá ao investidor individual ou institucional ${ }^{8}$ a segurança de que seus investimentos tenham liquidez, permitindo mudanças esporádicas - se não diárias - dos seus portfólios ${ }^{9}$ sem se confrontarem com perdas expressivas de valor. ${ }^{10}$

No interior dessa institucionalidade, os problemas associados ao "dilema da liquidez" continuam a criar contradições e vulnerabilidades. Por exemplo, na narrativa de Keynes (1937), a facilidade na compra e venda de títulos, importante para viabilizar o funding do investimento, depende da existência de um grande volume diário de operações. Os grandes volumes de operações, por sua vez, são alcançados com a participação de uma classe de investidores de curto prazo que visa ganhos de capital em vez do retorno de longo prazo dos ativos - os chamados especuladores. A lógica desses últimos se volta para a antecipação das oscilações de preços decorrentes das reavaliações permanentes em um ambiente tipicamente incerto. Quanto maior for a liberdade que encontram para construir suas estratégias, mais dinheiro dirigem para as bolsas, contribuindo com a intensidade.

Entretanto, se o papel dos especuladores é essencial ao funcionamento do circuito finance-funding, sua liberdade de ação e atuação pode, frequentemente, exacerbar mo-

8 Investidores institucionais são, por exemplo, os fundos de pensão, as seguradoras e os fundos de investimento. Em geral, são agentes que, pela estrutura de seus "passivos contingentes", querem manter em suas carteiras tais títulos por prazo longo. São esses agentes que, quase sempre, dão profundidade ao mercado - como discutiremos a seguir.

9 Evidentemente na prática, a distinção de mercados primário e secundários é irrelevante, já que para a grande parte das operações de compra e venda de títulos se dá em uma só plataforma de negociação.

${ }_{10}$ Nesse sentido, o circuito finance-funding, como orginalmente descrito, assume uma estrutura institucional muito familiar àquela que Keynes conhecia bem, como economista e como investidor. Trata-se do modelo que se desenvolveu na Inglaterra e nos Estados Unidos: sistemas financeiros com mercados de valores mobiliários. Nessa institucionalidade, a possibilidade de colocação em massa de títulos amplia substancialmente o leque de opções dos empresários - especialmente os de maior porte - para financiar seus investimentos. 
vimentos de preços e, eventualmente, provocar pânico entre o conjunto dos operadores. A volatilidade dos preços dos ativos e/ou a dificuldade para encontrar compradores dos ativos acabam por reduzir brutalmente a liquidez e a eficiência dos mercados. Ou seja, a atividade especulativa, necessária para dar liquidez a ativos fundamentalmente ilíquidos pode inibir a atuação de investidores mais avessos ao risco de capital como, por exemplo, fundos de pensão e seguradoras, ${ }^{11}$ obstruindo um canal relevante para o funding do investimento. Por sua vez, um ambiente mais volátil estimula ainda mais a presença de especuladores nas operações de compra e da venda, interferindo na evolução dos preços dos ativos de forma decisiva. ${ }^{12}$ No limite, os próprios investidores institucionais, inevitavelmente, deverão levar em conta a lógica da especulação para escolher o melhor momento para comprar ou vender ativos e, eventualmente, mudar o seu foco para o curto prazo e operar também como especuladores. ${ }^{13}$

Em suma, o financiamento da acumulação calcada em mercados de capitais exige uma institucionalidade complexa, que, simultaneamente, promova a eficiência macroeconômica do sistema (que é o funding) e mitigue os riscos de bolhas e crises financeiras. Seu desenvolvimento é uma exceção histórica - e não é um resultado "natural" das forças "livres" de mercado. De fato, a necessidade de funding foi historicamente resolvida por muitos outros sistemas financeiros que nunca possuíram mercados de capitais profundos como o paradigma institucional utilizado - por razoes didáticas, cremos - por Keynes. ${ }^{14}$

A "fragilidade financeira" inerente aos sistemas de financiamento da acumulação nas economias de mercado é um tema importante que Hyman Minsky e seus discípulos desenvolveram ao longo dos anos e que ganhou bastante espaço no debate econômico depois da crise financeira global, de 2008. Mas, dessa discussão dos mecanismos de finance-funding, é importante ressaltar um tema especialmente caro aos que pensam em políticas de desenvolvimento financeiro: o fato de Keynes utilizar um modelo institucional específico para sua narrativa do circuito finance-funding não significa

11 Não é, portanto, casual o fato de que o crescimento do mercado de capitais norte-americano se deu com expansão simultânea da abertura de capitais das empresas e crescimento dos investidores institucionais. Voltaremos a esta questão abaixo.

12 A especulação "excessiva” pode também gerar bolhas. Essas terminam por gerar crises financeiras que podem engendrar drásticas quedas do investimento, produção e emprego - como Hyman Minsky demonstraria quase cinquenta anos depois da publicação da Teoria Geral.

13 Alternativamente, na medida em que surgem oportunidades especulativas, mesmo os investidores institucionais não podem desconsiderá-las, ainda que seus objetivos sejam de mais longo prazo. Ou seja, a depender da regulação e do ambiente econômico, investidores institucionais também podem atuar como especuladores. E, muitas vezes, é essencial que assim o façam (KEYNES, 1936).

14 Sobre um destes arranjos falamos a seguir, veja-se Zysman (1983) e Schumpeter (1939). 
que a existência de mecanismos de funding por mercado de capitais expresse uma "funcionalidade" superior desta institucionalidade (STUDART, 1995).

Voltaremos a este tema da institucionalidade. Contudo, seria impossível ter uma visão clara sobre o tema de financiamento da acumulação na obra de Cardim sem falarmos um pouco mais sobre um tema recorrente de sua obra e extremamente importante na discussão da "funcionalidade do sistema financeiro": a distinção entre incerteza e risco nas estratégias de alocação de recursos financeiros e seu impacto potencial sobre a provisão de liquidez e o funding.

\section{RISCO, INCERTEZA E FUNDING}

Como Cardim de Carvalho ressaltou em distintos momentos (CARVALHO 1988 e 1992), a peculiaridade da perspectiva pós-Keynesiana sobre o financiamento da acumulação não advém somente do princípio da demanda efetiva e da reversão causal entre finance e poupança agregada. Para fechar esse quadro analítico é preciso entender a distinção entre os conceitos de risco e de incerteza (não redutível a risco) - e, principalmente, como são utilizados para descrever a dinâmica e o papel de distintos agentes e instituições no financiamento da acumulação. Como quase tudo na vida, podemos chegar ao tema por diversos caminhos. Talvez a melhor forma de o fazer seja resgatar os pilares da moderna teoria das finanças - que tem como principais variáveis a dupla risco e retorno esperado. ${ }^{15}$ Isso também nos permite um diálogo que vai além dos autores pós-Keynesianos.

Risco é um indicador da distribuição de frequência de eventos financeiros passados, especialmente os relacionados à capacidade de repagamento dos agentes tomadores de recurso. Por outro lado, retorno esperado é uma extrapolação da performance passada de setores produtivos. Ambos são utilizados para definir a decisão de investimento e de alocação de portfólio - que são apostas em relação ao futuro. De fato, esses conceitos podem ser úteis em fases de "calmaria macrofinanceira", isto é, quando se define um estado de normalidade e com transformações previsíveis. Eles orientam o comprador de ativos financeiros quando os mercados financeiros têm baixa volatilidade, ou o investidor produtivo quando o crescimento é basicamente determinado por investimentos de recomposição de capacidade produtiva e/ou manutenção/expansão de infraestrutura, em ambiente de relativa "estabilidade tecnológica". Nesses contextos, tais indicadores po-

15 Para uma discussão elementar da atual teoria das finanças, veja Carvalho et al. (2015, cap. 11). 
dem, sim, suprir os hiatos de informação geradas por investimentos tecnologicamente disruptivos ou que geram mudanças estruturais - que não sejam sistêmicas.

Porém, esses conceitos são os menos úteis para as decisões de investir e financiar quando nos referimos a investimentos que levam a mudanças sistemicamente importantes. Nesses casos, mais do que consolidar trajetórias de crescimento existentes, as decisões de investir e financiar criam novas trajetórias possíveis que, por sua vez, fazem com que os eventos e evidências do passado sejam de pouca serventia para projetar o futuro em construção. São investimentos cuja análise tradicional de risco e retorno esperado é uma guia pouco útil. Para a decisão da execução e do financiamento desses investimentos, o espírito animal forma a essência da eficiência marginal do capital e da preferência pela liquidez dos bancos e mercados de títulos financeiros.

É quando se discute o tema de financiamento da acumulação que fica ainda mais clara a originalidade pós-Keynesiana - inclusive em relação a outros tipos de Keynesianismo. Por exemplo, para os chamados neokeynesianos, a eficiência macroeconômica do sistema financeira advém, supostamente, da sua capacidade em dirimir os riscos associados à inexistência ou assimetria de informações. ${ }^{16}$ Foi nesse sentido que Stiglitz e Weiss (1981) originariamente desenvolveram toda a discussão sobre as consequências das assimetrias de informação - dentre elas, o racionamento de crédito. $\mathrm{O}$ argumento é atraente tanto para os adeptos da síntese neoclássica, quanto para os Keynesiana favoráveis a uma intervenção mais contundente do Estado para enfrentar $f a$ lhas de mercado. E, por isso, os desdobramentos matemáticos elegantes tiveram e tem até hoje tantos adeptos.

Para os pós-Keynesianos, a problemática em torno do financiamento da acumulação vai muito além da distribuição de informação. ${ }^{17}$ E remete às consequências da incerteza sobre a forma de teorizar qualquer tema que envolva economias de mercado - a começar com temas monetários e financeiros. Para ilustrar essa diferença de abordagem, quando aplicada ao tema do financiamento da acumulação, utilizamos o Quadro

16 Os modelos neokeynesianos têm como ponto de partida um modelo de equilíbrio geral Walrasiano. Neles, conquanto haja competição perfeita e flexibilidade de preços, pode-se demonstrar que é possível alcançar um equilíbrio simultâneo para todos os mercados. No "mercado financeiro", esse equilíbrio ocorre quando a taxa de juros real é igual à natural, que equilibra poupança e investimento agregados em pleno emprego. O que fazem Stiglitz e Weiss, de forma absolutamente brilhante, é relativizar a hipótese de perfeita distribuição de informações para introduzir os problemas de assimetria de informações.

17 É sempre bom lembrar que o que distingue os pós-Keynesianos não é, por si só, o conceito de incerteza - conhecido e utilizado em todas as análises econômicas. É, sim, não reduzir a incerteza - com todas as suas implicações para as decisões de investir e financiar - ao conceito de risco probabilístico da ocorrência de eventos futuros. Como veremos, distinguir esses conceitos é o que torna ricos e fundamentais a análise da institucionalidade e o papel das políticas em ampliar a funcionalidade do sistema financeiro. Mais uma vez remetemos à leitura de Carvalho (1992) para essa discussão. 
1 a seguir. Dialogando com a teoria moderna da informação, nele classificamos situações distintas de incerteza, segundo a possibilidade de reduzi-las a risco.

Assim, a primeira (Tipo I) incluiria os casos redutíveis ao risco, enquanto a segunda (Tipo II) incluiria aqueles que não o são. A incerteza de Tipo I engloba o financiamento ou o investimento em empresas e setores estabelecidos, com histórico de performance, em geral, registrado em balanços periódicos, que pretendem realizar investimentos marginais e oferecem garantias reais relativamente altas. O caso é diferente daquele em que se trata de novas empresas, que não possuem um histórico de performance e, em geral, disponibilizam garantias pouco significativas perante os riscos assumidos, constituindo aquelas situações de incerteza do Tipo II.

\begin{tabular}{lll}
\multicolumn{2}{c}{ Quadro 1 - Problemas “informacionais” no crescimento com mudanças estruturais } \\
\hline \multicolumn{1}{c}{ Tipo I } & \multicolumn{1}{c}{ Tipo II } \\
\hline $\begin{array}{l}\text { Tipos de } \\
\text { demanda por } \\
\text { financiamentos }\end{array}$ & $\begin{array}{l}\text { Empresas e setores estabelecidos com } \\
\text { investimento marginais e garantias reais } \\
\text { relativamente altas }\end{array}$ & $\begin{array}{l}\text { Criação de novas empresas, setores; entrada em } \\
\text { setores com barreiras à entrada determinadas por } \\
\text { custos de aprendizado e economias de escala; ou } \\
\text { entrada em novos mercados; garantias reais } \\
\text { relativamente baixas }\end{array}$ \\
$\begin{array}{lll}\text { Problemas } \\
\text { informacionais }\end{array}$ & $\begin{array}{l}\text { Problemas de distribuição de informações } \\
\text { (assimetria de informações etc.) }\end{array}$ & $\begin{array}{l}\text { As informações do passado não são guias adequados } \\
\text { para projeçóes sobre performance futuras de } \\
\text { empresas investidoras }\end{array}$ \\
\hline $\begin{array}{l}\text { Falhas possíveis } \\
\text { de } \\
\text { intermediação }\end{array}$ & $\begin{array}{l}\text { Problemas de monitoramento, seleção e } \\
\text { empréstimo; incompletude ou inexistência } \\
\text { de mercados; competição imperfeita; } \\
\text { racionamento de crédito gerado por } \\
\text { crescimento acelerado da vulnerabilidade } \\
\text { financeira dos bancos comerciais }\end{array}$ & $\begin{array}{l}\text { Incapacidade de avaliação de risco, gerando } \\
\text { inexistência de fontes privadas de financiamento }\end{array}$ \\
\hline
\end{tabular}

Fonte: Elaborado pelos autores com base em Studart (2003).

Independentemente da "profundidade" e da sofisticação da estrutura financeira, problemas informacionais do Tipo II dificultam a decisão de financiar ou investir com base na análise de retorno esperado versus risco. Este resultado não pode ser considerado uma falha de mercado: a própria hipótese de mercados eficientes se calca na imagem de que instituições e mercados financeiros privados são eficientes na coleta, processamento e distribuição de informações - e não em situações em que os eventos passados são guias pouco apropriados para projetar o futuro. Evidentemente, o financiamento da acumulação, especialmente em momentos "schumpeterianos" de mudanças estruturais, envolve muito mais situações do Tipo I do que as do Tipo II.

É a partir dessa perspectiva que também podemos entender o potencial das intervenções de política no sentido de aprimorar as condições de financiamento da acumulação - por exemplo, quando se criam mecanismos para oferecer condições de crédito atrativas a investimentos que promovem mudanças estruturais, que podem permitir a 
criação de novos setores e trajetórias de crescimento, ou seja, um horizonte de longo prazo para o planejamento do investimento e da alocação de portfólios. Para dialogar com os autores que se utilização das teorias da informação para formular sobre o tema, podemos dizer que tais políticas criam novas informações, possibilitando aos agentes se organizarem e planejarem seu futuro a partir de seus comportamentos maximizadores - uma função que Aoki, Murdock e Okuno-Fukiwara (1995) denominaram políticas de adensamento de mercado (market-enhancement)

Outro tipo de política se associa ao desenvolvimento de mercados - voltadas a criar ou acelerar o desenvolvimento de instrumentos e mercados, facilitando a formação de mecanismos de finance e funding com recursos privados. Essas políticas vão desde o desenvolvimento de regulamentação e mecanismos de supervisão adequados, até o incentivo à criação e ao desenvolvimento de mercados de títulos de longo prazo. ${ }^{18}$ Na medida em que os investidores institucionais são fundamentais na consolidação de tais mercados, tais políticas devem também estar voltadas a incentivos (regulatórios e outros) no sentido de criar pontes com e incentivo para investidores institucionais. ${ }^{19}$

Para Cardim, a longo de sua obra (e.g. CARVALHO, 1992, 1997, 2016) a problemática em torno do financiamento da acumulação vai muito além da intermediação financeira, da distribuição de informação e do binômio risco-retorno. Ela abarca a problematização do papel de distintas configurações institucionais como forma de mitigar a incerteza não-redutível inerente ao processo, do papel do desenvolvimento institucional - determinado por forças de mercado ou por intervenções públicas -, e do papel das políticas que afetem o custo de financiamento da acumulação. Apesar de sua análise poder ser aplicada a distintos tipos de "economias de mercado", ela é fundamental para aqueles que pretendem analisar o tema no contexto de desenvolvimento - que em geral caracteriza por transformações produtivas e sociais que acabam fazendo com que instituições, instrumentos e políticas voltadas para o setor financeiro sejam especialmente importantes na determinação das possibilidades de desenvolvimento econômico e social.

18 Um exemplo nesse sentido foi o desenvolvimento dos mercados de ativos lastreados em hipoteca que constituem a base do sistema de financiamento imobiliário norte-americano atual - como demonstra Feeney (1995, cap. 5).

19 Essas funções do ativismo público são discutidas em Studart (2003) e, mais recentemente, no mesmo sentido, em Mazzucato e Penna (2018). Para exemplos de tais tipos de políticas implementadas por diversos bancos de desenvolvimento no mundo, inclusive o BNDES, veja-se Griffith-Jones et al. (2018). 


\section{CONCLUSÃO}

Como economista, mestre e mentor, Cardim sempre alertara para os perigos de esquecermos este fundamento básico da Teoria Geral. Por exemplo:

Generations of economists have been trained in macro and monetary economics through the use of (...) models where stable relations (...) are assumed by construction. (...) [without considering] (...) the ways in which perceived uncertainty can affect the demand for money and, thus, the level of interest rates. (CARVALHO, 2009, p. 722)

A partir dessa visão crítica sobre a economia tal como é ensinada, inclusive as leituras mais convencionais da obra revolucionária de Keynes, Cardim nos remete às consequências da incerteza sobre a forma de teorizar qualquer tema que envolva economias de mercado - a começar com temas monetários e financeiros.

Ao longo da sua obra, Cardim recorrentemente revisita o tema do financiamento da acumulação - causa causans da dinâmica das economias empresariais. E sempre nesse processo, dois atores são tidos como primordiais: o investidor produtivo e o sistema financeiro. Esse último, verdadeiro pulmão do sistema de mercado, aparece como um facilitador ou um limitante da acumulação nos ciclos econômicos. Mais uma vez, Cardim é conciso, mas preciso:

The financial system - that is, the set of financial institutions and markets, their practices, and interrelations - or a modern, monetary economy must be organized to meet the demands of the process of capital formation. This means that it must be prepared to make available the necessary finance for the investment process to start, that is, to provide investors with the money required for the planned investment expenditures to take place and to allow the investors' debts to be adequately funded. (CARVALHO, 1997, p. 472)

O caminho para entender este papel na obra daquele autor não é linear. Isso porque Cardim, como grande intelectual que era, não trata a questão como um único tema, mas olhando por diversos ângulos: o da dinâmica macroeconômica, calcada no princípio da demanda efetiva; o da teoria da probabilidade, e o papel da incerteza na definição da tomada de decisão, inclusivo de agentes dentro do sistema financeiro; o do desenvolvimento institucional que leva a inovações financeiras, que terminam por redefinir a forma como se processa o financiamento da acumulação em economias de mercado.

Como economista político, Cardim oferece uma contribuição teórica ao entendimento deste - e outros temas caros aos economistas - que se revela um instrumento 
importante para se pensar políticas públicas. Permite, por exemplo, compreender como essas políticas podem contribuir com a consolidação de setores produtivos e financeiros, criando novos horizontes de investimento produtivo e desenvolvimento. Além disso, explicita como inovações financeiras, somadas a regulações inteligentes, permitem o desenvolvimento de novas instituições, mercados e instrumentos voltados a mitigar problemas no circuito de financiamento e funding da acumulação.

Como mestre e mentor intelectual, Cardim nunca se satisfez em entregar aos seus alunos, leitores e discípulos receitas prontas - ou requentadas - para entender temas complexas e enfrentar problemas de políticas. Pelo contrário, sempre ofereceu suas análises de Keynes e outros clássicos como plataforma para a rigorosa reflexão e para, quando necessário, a construção de soluções de políticas. Foram muitos os seus alunos que, em momentos como estes, voltaram a reler seus artigos e notas sobre suas aulas para poder estabelecer seus próprios caminhos e soluções.

Por fim, se Cardim dificilmente pode ser substituído nessas distintas categorias, como amigo é de fato insubstituível. Aqueles que conheceram Fernando podem compartilhar os inúmeros momentos em que o apoio e a dedicação pessoal do mestre permitiram, de uma forma e de outra, ultrapassar dificuldades - tão comuns num país em que a vida acadêmica tem historicamente pouco apoio. Estes dois autores são testemunhas dessa qualidade humana deste grande mestre, economista político, intelectual - e do grande amigo por quem uma enorme gratidão e tantas saudades sempre teremos.

\section{REFERÊNCIAS}

AOKI, M.; MURDOCK, K.; OKUNO-FUJIWARA, M. Beyond the East Asian miracle: introducing the market enhancing view. Stanford, CA: Center for Economic Policy Research, Stanford University, 1996. Mimeo.

CARVALHO, F. J. C. Keynes on probability, uncertainty, and decision-making. Journal of Post Keynesian Economics, v. 11, n. 1, p. 166-180, 1988.

CARVALHO, F. J. C. Keynes and the long period. Cambridge Journal of Economics, v. 14, n. 3, p. 277-290, 1990.

CARVALHO, F. J. C. Mr. Keynes and the post Keynesians: principles of economics for a monetary production economy. Aldershot: Edward Elgar, 1992.

CARVALHO, F. J. C. Sorting out the issues: the two debates (1936/37; 1983-86) on Keynes's finance motive revisited. Revista Brasileira de Economia, v. 50, n. 3, p. 312-327, 1996.

CARVALHO, F. J. C. Financial innovation and the post Keynesian approach to the "process of capital formation”. Journal of Post Keynesian Economics, v. 19, n. 3, p. 461-487, 1997.

CARVALHO, F. J. C. Uncertainty and money: Keynes, Tobin and Kahn and the disappearance of the precautionary demand for money from liquidity preference theory. Cambridge Journal of Economics, v. 34, n. 4, p. 709-725, 2009a. 
CARVALHO, F. J. C. Systemic crisis, systemic risk and the financial instability hypothesis. In: HEIN, E.; NEICHOJ, T.; STOCKHAMMER, E. (Eds.) Macroeconomic policies on shaky foundations: wither mainstream economics? Marburg: Metropolis, $2009 \mathrm{~b}$.

CARVALHO, F. J. C. Aggregate savings, finance and investment. European Journal of Economics and Economic Policies: Intervention, v. 9, n. 2, p. 197-213, 2012.

CARVALHO, F. J. C. Liquidity preference and monetary economics. London: Routledge, 2015.

CARVALHO, F. J. C. On the nature and role of financial systems in Keynes's entrepreneurial economies. Journal of Post Keynesian Economics, v. 39, n. 3, p. 287-307, 2016.

CARVALHO, F. J. C. et al. Economia monetária e financeira: teoria e política. 3. ed. Rio de Janeiro: Elsevier, 2015.

CARVALHO, F. J. C.; KREGEL, J.; CASTRO, L. B.; STUDART, R. Development finance: theory and practice. In: NISSANKE, M.; OCAMPO, J. A. (Eds) The Palgrave Handbook of Development Economics - critical reflections on globalization and development. London: Palgrave Macmillan, 2019.

CHICK, $\mathrm{V}$. The evolution of the banking system and the theory of saving, investment and interest. Economies et Sociétés, v. 3, n. 8-9, p. 111-126, 1986.

CHICK, V. The evolution of the banking system and the theory of monetary policy. In: FROWEN, S. (Ed.) Monetary theory and monetary policy: new tracks in the 1990s. Basingstoke, UK: St. Martin’s Press, 1993, p. 79-92.

FEENEY, P. W. Securitization: redefining the bank. London: Palgrave McMillan, 1995.

GRIFFITH-JONES, S. ET AL. The future of national development banks. In: GRIFFITH-JONES, S.; OCAMPO, J. A. (Eds.) The future of national development banks. Oxford: Oxford University Press, 2018.

GURLEY, J. G.; SHAW, E. S. Financial aspects of economic development. The American Economic Review, v. 45, n. 4, p. 515-538, 1955.

KEYNES, J. M. The general theory of employment, interest and money. London: McMillan, 1947[1936].

KEYNES, J. M. The "ex-ante" theory of the rate of interest. The Economic Journal, Dec. 1937.

MAZZUCATO, M.; PENNA, C. National development banks, and mission-oriented finance for innovation. In: GRIFFITH-JONES, S.; OCAMPO, J. A. (Eds.) The future of national development banks. Oxford: Oxford University Press, 2018.

MINSKY, H. P. Can it happen again? Essays on Stability and Finance. New York: M. E. Sharpe, 1982.

MOORE, B. Horizontalists and verticalists: the macroeconomics of credit. Cambridge, UK: Cambridge University Press, 1988.

SCHUMPETER, J. Business cycles: a theoretical, historical and statistical analysis of the capitalist process. New York and London: McGraw-Hill, 1939.

STIGLITZ, J. E. The role of the State in financial markets. In: Proceeding of the World Bank Annual Conference on Development Economics 1993. Washington, D.C.: The World Bank, 1994, p. 19-52. 
STIGLITZ, J. E.; WEISS, A. Credit rationing in markets with imperfect competition. American Economic Review, v. 71, n. 5, p. 393-410, 1981.

STUDART, R. The efficiency of the financial system, liberalization and economic development. Journal of Post Keynesian Economics, v.18, n. 2, p. 265-289, Winter 1995.

STUDART, R. Estado, mercados e o financiamento da acumulação, algumas considerações. In: CICLO DE SEMINÁRIOS 2003 - BRASIL EM DESENVOLVIMENTO. Rio de Janeiro: IEUFRJ, CEPAL, 2003. Disponível em: <https://bit.ly/2D4JlWz $>$.

ZYSMAN, J. Governments, markets, and growth: financial systems and the politics of industrial growth. Oxford: Martin Robertson, 1983. 